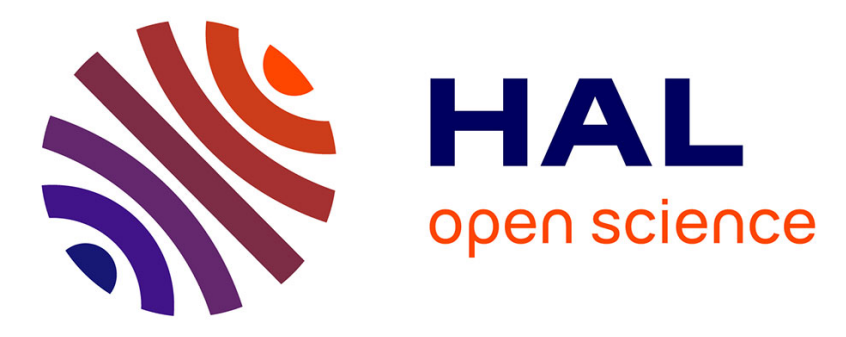

\title{
Smart wearable active patch for elderly health prevention
}

Christophe Escriba, Julien Roux, Bouchta Hajjine, Jean-Yves Fourniols

\section{To cite this version:}

Christophe Escriba, Julien Roux, Bouchta Hajjine, Jean-Yves Fourniols. Smart wearable active patch for elderly health prevention. 5th Annual Conference on Computational Science \& Computational Intelligence (CSCI'18), Dec 2018, Las Vegas, United States. hal-02015896

\section{HAL Id: hal-02015896 https://hal.laas.fr/hal-02015896}

Submitted on 12 Feb 2019

HAL is a multi-disciplinary open access archive for the deposit and dissemination of scientific research documents, whether they are published or not. The documents may come from teaching and research institutions in France or abroad, or from public or private research centers.
L'archive ouverte pluridisciplinaire HAL, est destinée au dépôt et à la diffusion de documents scientifiques de niveau recherche, publiés ou non, émanant des établissements d'enseignement et de recherche français ou étrangers, des laboratoires publics ou privés. 


\section{Smart wearable active patch for elderly health prevention \\ Short paper - CSCI ISOT}

\author{
Christophe ESCRIBA \\ LAAS-CNRS, Université de \\ Toulouse, CNRS, INSA, \\ Toulouse, France \\ cescriba@laas.fr
}

\author{
Julien ROUX \\ LAAS-CNRS, Université de \\ Toulouse, CNRS, UT2J, \\ UT2J, Toulouse, France \\ jroux@laas.fr
}

\author{
Bouchta HAJJINE \\ LAAS-CNRS, Université de \\ Toulouse, CNRS, INSA, \\ Toulouse, France \\ bhajjine@laas.fr
}

Jean-Yves FOURNIOLS

LAAS-CNRS, Université de

Toulouse, CNRS, INSA,

Toulouse, France

fourniols@laas.fr

\begin{abstract}
This paper presents the development of a miniaturized electronic patch for dependent persons and elderly surveillance. This waterproof system can be wirelessly charged using magnetic induction and is able to automatically detect fall cases, ensure a GPS geolocation, and trigger alarms based on Sigfox low consumption network.
\end{abstract}

\section{Keywords-patch, waterproof, fall, GPS geolocation, alarms}

\section{INTRODUCTION}

France like some others countries witnesses an increasing level of elderly people due to the big development that have known scientific and economic sectors and the arrival to the retirement age of the babyboom generation that was born after the second world war [1]. Aging is always related to health problems and dependence that demand a permanent monitoring in aim to ensure an immediate intervention in dangerous situations such as falls that threaten seriously elderly life or fugues in the case of people suffering from cognitive disease. Using advanced technologies to help dependent persons can alleviate these problems and provide suitable solutions that can guarantee this kind of service. Several systems have been developed based on the monitored persons like falls detectors [2], daily activities [3], blood pressure [4], trackers $[5], \ldots$

In this paper, we will focus on the conception of an electronic patch for falls detection and GPS tracking as a part of a research project named SACHA (Search And Computerize Human Acts) [6]. We will present the different characteristics of this patch and some related tests and results.

\section{FUNCTIONALITIES OF THE PATCH}

Our patch is a waterproof system that was developed to be worn permanently with a specific emplacement between shoulders blades to avoid any try to take it off in the case of people suffering from cognitive problems. It provides two main functionalities: falls detections using a 3D accelerometer and tracking based on GPS when the monitored person exceeds a predefined safety zone. Different alarms and data messages are transmitted via a very low consumption IOT network: Sigfox as presented in Figure 1.

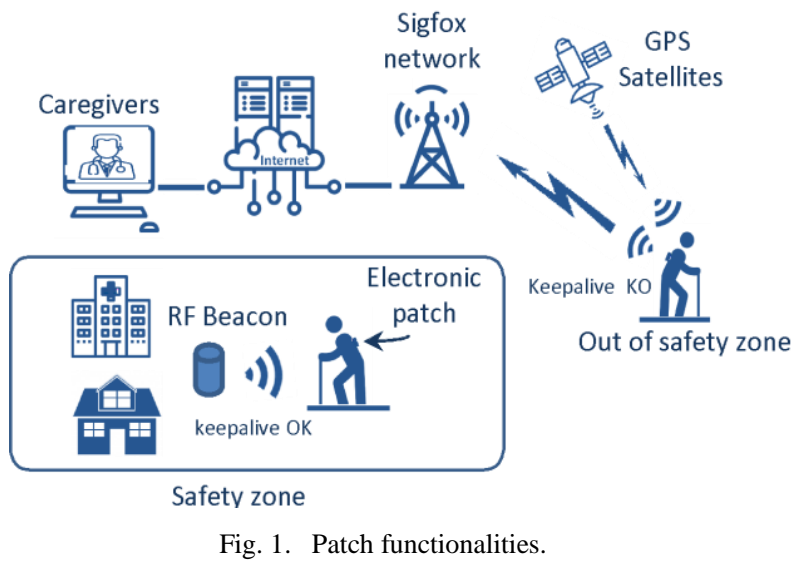

The safety zone size can be defined by a configurable RF link between the patch and a beacon to be put in the dependent person residence.

The proposed patch is characterized with a small size of 58 $\times 26 \mathrm{~mm}^{2}$ and it integrates a very thin battery with a capacity of $30 \mathrm{mAh}$ that can ensure a permanent monitoring during 3 days or 13 hours in the case of GPS tracking activation.

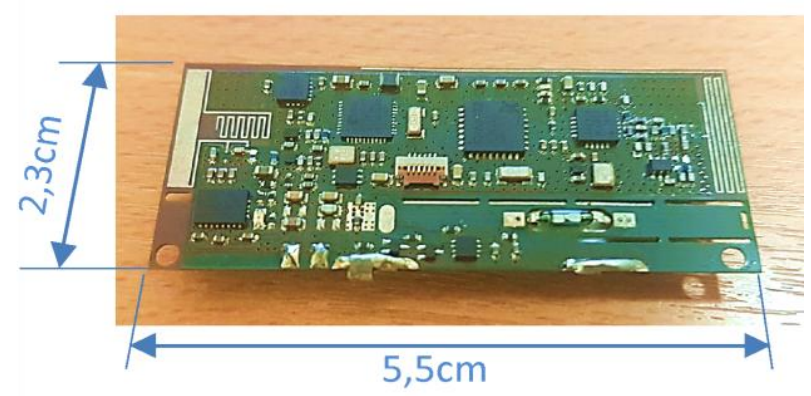

Fig. 2. Electronic patch for fall detection and GPS tracking.

\section{DESIGN OF 868MHZ AND GPS ANTENNAS}

The patch integrates two printed inverted $\mathrm{F}$ antennas (PIFA) with operating frequencies of $868 \mathrm{MHz}$ (Sigfox) and 1575.42 MHz (GPS). They were designed and simulated using Keysight ADS RF Software (Figure 3). 


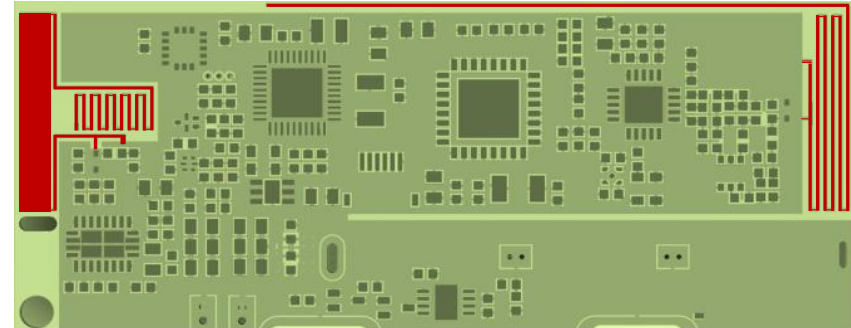

Fig. 3. Design of Sigfox and GPS antennas.

The both antennas were meandered many times to reduce their size. The simulated reflection coefficients S11, bandwidth, and gains are summarized in Table 1.

TABLE I SIMULATED CHARACTERISTICS OF 868MHZ AND GPS ANTENNAS.

\begin{tabular}{|l|c|c|c|}
\cline { 2 - 4 } \multicolumn{1}{c|}{} & $\begin{array}{c}\text { Reflection coefficient } \\
\text { S11 }\end{array}$ & Bandwidth & Gain \\
\hline SIGFOX antenna & $-38 \mathrm{~dB}$ & $7.3 \mathrm{MHz}$ & $-6.9 \mathrm{dBi}$ \\
\hline GPS antenna & $-36.8 \mathrm{~dB}$ & $25 \mathrm{MHz}$ & $0.6 \mathrm{dBi}$ \\
\hline
\end{tabular}

After the fabrication of the patch PCB, a matching process using a vector network analyzer (VNA) is necessary to take into account the different parameters that can influence antennas characteristics: packaging, battery, human body effect. The measured reflection coefficients are presented in Figure 4. The both antennas have good S11 values: -16.4 $\mathrm{dB}$ for the Sigfox antenna and $-20 \mathrm{~dB}$ for the GPS one.

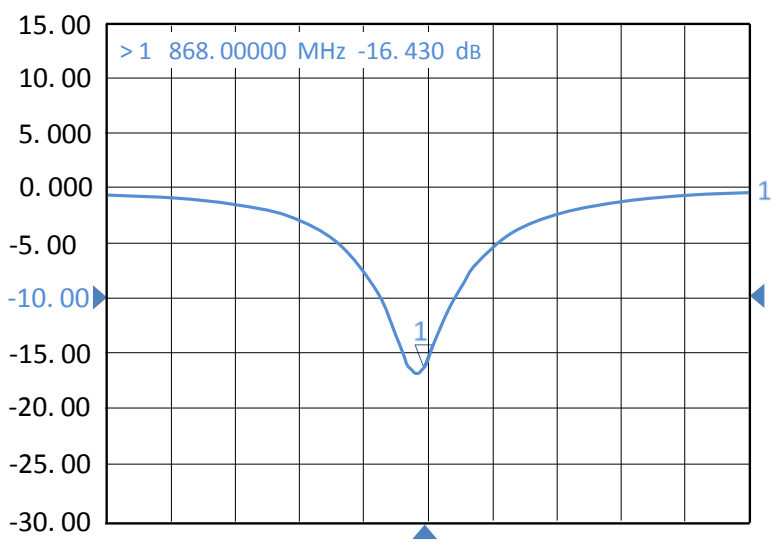

(a)

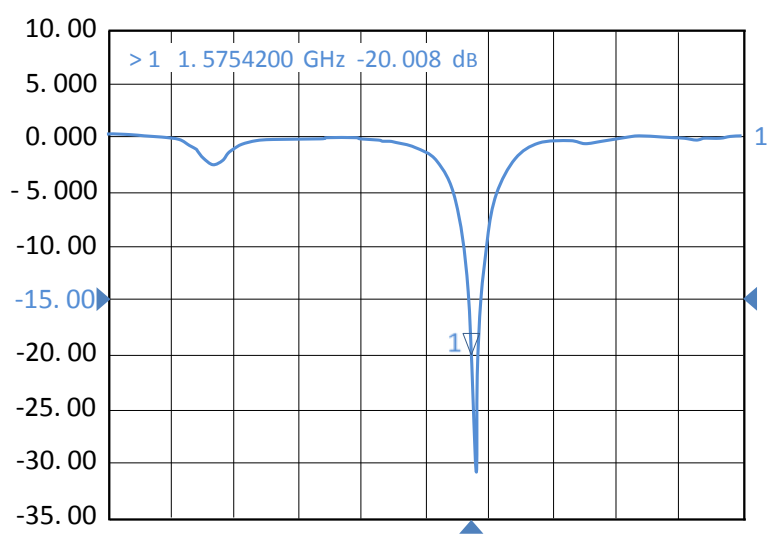

(b)

Fig. 4. Measured reflection coefficients of Sigfox antenna (a) and GPS antenna (b).
Several tests were made in real cases to validate the good functioning of the patch. One of these tests is based on sending 10 alerts from different position around our laboratory and then verifies the number of frames received by Sigfox stations. The different results are presented in Figure 5 .

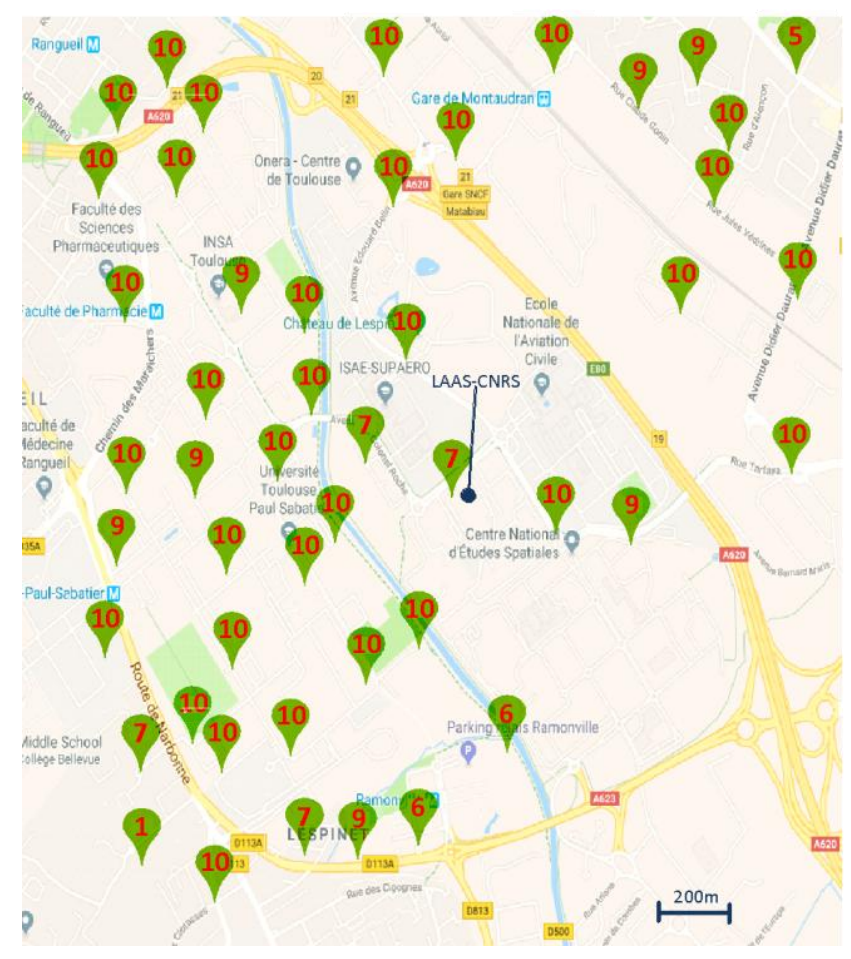

Fig. 5. Communication test between the patch and Sigfox stations.

For $67.92 \%$ of the tested positions we were able to receive all the 10 sent messages and only in $3.77 \%$ of the tested points we received a number of alerts lower than 5 . This test validates the good functioning of the patch and its ability to communicate via Sigfox network.

\section{PRINTED COIL FOR WIRELESS POWER TRANSFER}

The patch battery is intended to be charged wirelessly in 4-5 hours with the Qi protocol. The necessary energy is transmitted using magnetic induction between a transmitting coil (charging pad) and a receiving coil integrated in the patch.

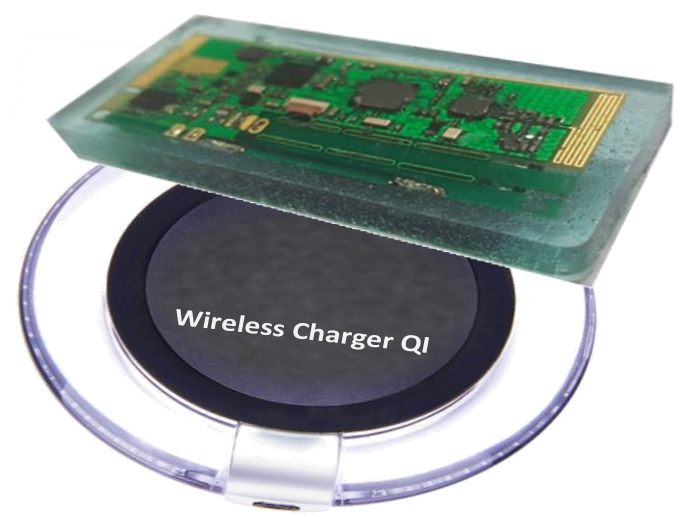

Fig. 6. Wireless charging of the encapsulated electronic patch

In aim to meet the small dimension of the patch, a thin flexible printed coil was designed and fabricated in the 
cleanroom process of our laboratory [7]. It is composed of two copper layers with a dimension of $42.3 \times 17 \mathrm{~mm}^{2}$ separated with a thin layer of polyimide $(50 \mu \mathrm{m})$. The coil tracks have a thickness of $17 \mu \mathrm{m}$, a width of $520 \mu \mathrm{m}$ and an interline spacing of $80 \mu \mathrm{m}$. This coil is characterized with an inductance of $\mathrm{L}=10.8 \mu \mathrm{H}$ and a resistance of $\mathrm{R}=3.18 \mathrm{Ohms}$.
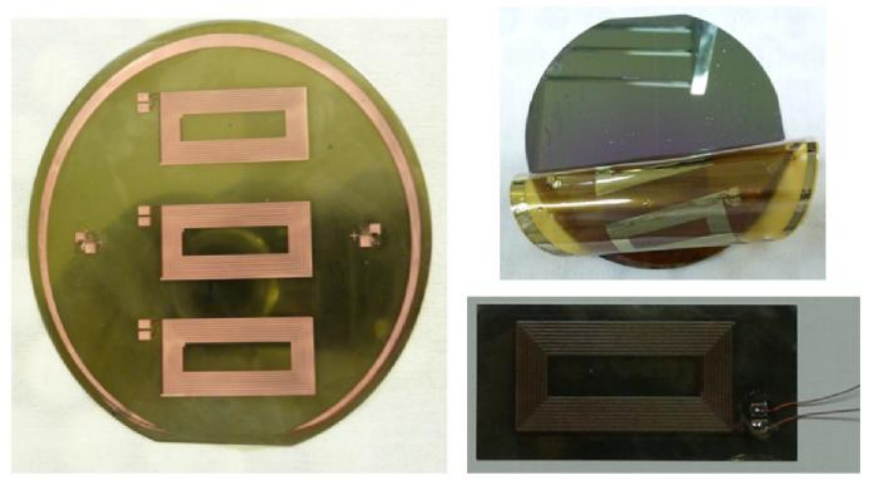

Fig. 7. Silicon wafer with three flex printed coils.

The charging current was adjusted to $7.5 \mathrm{~mA}$ in aim to ensure a full charging duration of 4-5 hours. Different tests were made in term of efficiency and maximum distance that can separate transmitting and receiving coils. The proposed coil can provide a convenient energy level to charge the patch battery up to a distance of $4.8 \mathrm{~mm}$ that is enough for our application.

The variation of the charging system efficiency as a function of the load current and printed tracks thickness is presented in Figure 8.

\section{Efficiency}

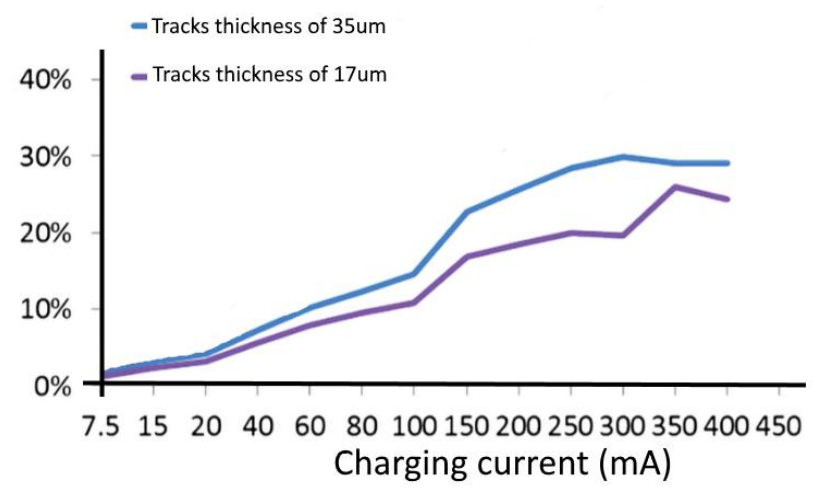

Fig. 8. Efficiency of the charging system using the proposed printed coil

The proposed printed coil does not provide a better efficiency compared to the commercialized bulky coils. Contrariwise, it is characterized with very small size ensuring a good functioning of the charging process in addition to a high degree of miniaturization for the tracking patch.

As all parts of the patch are exposed to the magnetic field of the charging pad, a thermal study was necessary to quantify temperature variation that can be caused by eddy currents in metallic areas.

The first test (Figure 9) shows that the PCB of the patch reaches a maximal temperature of $65.5{ }^{\circ} \mathrm{C}$ after only 6 min of wireless charging. This value is too high compared to the recommended maximal temperature of Li-po battery (45 $\left.{ }^{\circ} \mathrm{C}\right)$.

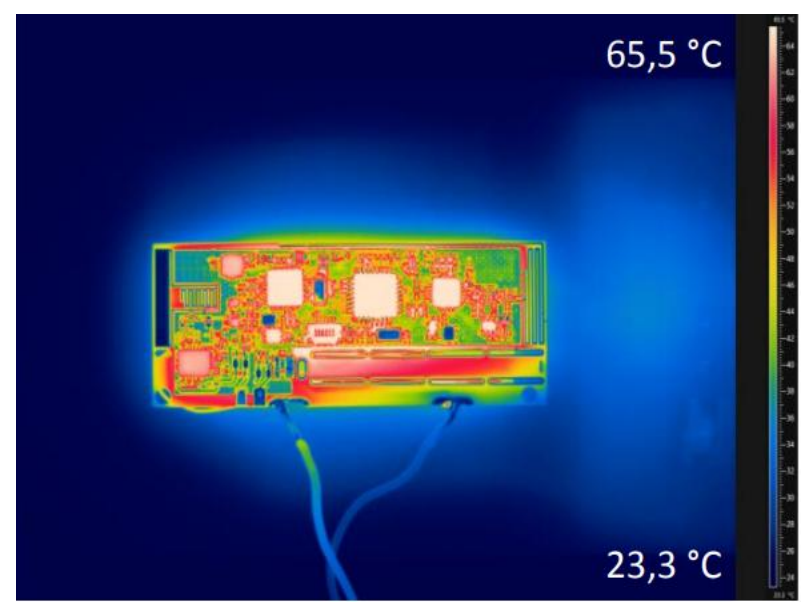

Fig. 9. Patch maximum temperature reached after 6 min of battery charging

In aim to avoid this problem of high temperature a ferrite layer was added between the coil and the battery. This layer plays the role of a magnetic guide to protect the patch from the magnetic field emitted by the charging pad as presented in Figure 10.

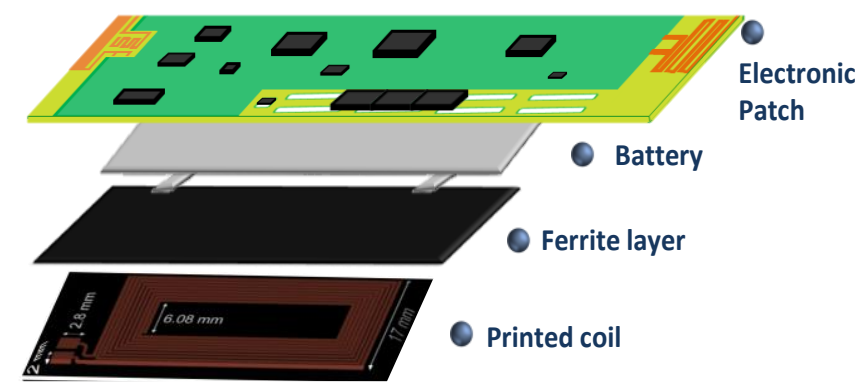

Fig. 10. Protection of the patch from magnetic field using a ferrite layer.

As presented in figure 11, the ferrite layer permits to limit the maximum temperature to $31{ }^{\circ} \mathrm{C}$ during the charging of the patch battery.

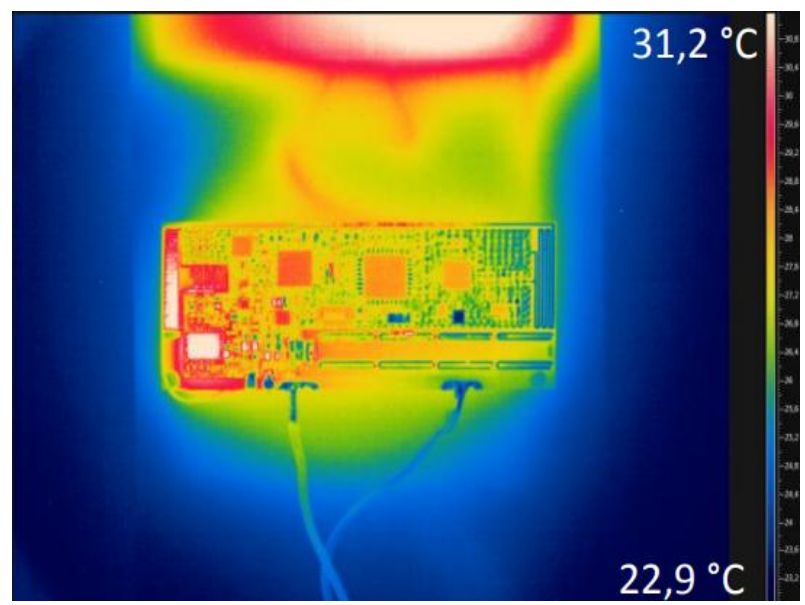

Fig. 11. Patch maximum temperature during the battery charging. 


\section{CONCLUSION}

This paper describes the development of a wearable electronic patch as a helping solution for elderly and dependent persons to alleviate falls and fugues problems. It includes two PIFA for Sigfox data transfer and GPS geolocation that were designed and validated with several real cases tests. The patch can be charged wirelessly using the Qi protocol to ensure waterproof characteristic. This functionality uses magnetic induction whose eddy currents were limited using a supplementary ferrite layer to limit the maximum temperature to an acceptable value during the battery charging.

\section{ACKNOWLEDGMENT}

This work is part of SACHA project funded by French government and "Région Midi Pyrénées" in France. The partners of the project are Sigfox, Axible, Telecom Design companies, Esanté and CHIVA hospital.

\section{REFERENCES}

[1] 'World Population Prospects 2017'. [Online]. Available: https://population.un.org/wpp/. [Accessed: 17- Oct- 2018].

[2] J. Santiago, E. Cotto, L. G. Jaimes and I. Vergara-Laurens, "Fall detection system for the elderly," 2017 IEEE 7th Annual Computing and Communication Workshop and Conference (CCWC), Las Vegas, NV, 2017, pp. 1-4.

[3] C. Debes, A. Merentitis, S. Sukhanov, M. Niessen, N. Frangiadakis and A. Bauer, "Monitoring Activities of Daily Living in Smart Homes: Understanding human behavior," in IEEE Signal Processing Magazine, vol. 33, no. 2, pp. 81-94, March 2016.

[4] C. Manlises, J. D. Cruz, J. Fausto, L. Muralla, D. Payas and M. Posada, "Monitoring of Blood Pressure Using Photoplethysmographic (PPG) Sensor with Aromatherapy Diffusion," 2016 6th IEEE International Conference on Control System, Computing and Engineering (ICCSCE), Batu Ferringhi, 2016, pp. 476-480.

[5] H. Wu, T. Hung, S. Wang and J. Wang, "Development of a shoebased dementia patient tracking and rescue system," 2018 IEEE International Conference on Applied System Invention (ICASI), Chiba, 2018, pp. 885-887.

[6] B. Hajjine. Conception, réalisation et intégration technologique d'un patch électronique : application à la surveillance des personnes âgées. Micro et nanotechnologies/Microélectronique. INSA de Toulouse, 2016. Français. .

[7] B. Hajjine, C. Escriba, S. Charlot, A. Hemeryck, J. Roux, S. Zedek and J.Y. Fourniols, (2016) Development of a Printed Coil for Wirelessly Charging a Tracking Elderly Patch. Wireless Engineering and Technology, 7, 83-9 